\title{
Resolution Enhancement of Input Parameters in a Demand Side Management Model
}

\author{
P. IMBERT ${ }^{1 \& 2}$ \\ (1): Geo simulation for Energy \\ European Institute for Energy Research - EIFER \\ Karlsruhe, Germany
}

\author{
G. KARINIOTAKIS ${ }^{2}$, P. BLANC ${ }^{2}$, F.P. NEIRAC ${ }^{2}$, \\ (2): Centre for Energy and Processes \\ MINES ParisTech \\ Sophia Antipolis, France
}

\begin{abstract}
Demand side management (DSM) and distributed generation (DG) introduce into power systems new dynamics and behaviors which must be taken into account in the planning and operation of the system. This paper presents a model that aims to simulate the spread out effects of DSM actions in a region. This model is suitable designed to represent the territorial or local specificities of each studied area where the DSM actions apply. The model involves a large number of input data. The main question is what should be the optimal level of detail this data has to be collected in terms of spatial resolution so that meaningful results are obtained. The paper presents a method to define the input data which are critical to collect with a higher spatial resolution. Results for a case study in France are presented.
\end{abstract}

Demand-side management, territorial energy planning, input parameter selection, sensitivity analysis, ranking based correlation method, Monte Carlo simulation.

\section{INTRODUCTION}

The unbundling of the electricity sector, increasing ecological and reliability of supply concerns, as well as advances in micro-generation and renewable energy technologies compose a favorable environment for the deployment of distributed generation (DG) into power systems. Nowadays, considerable research is being carried out for evaluating the benefits from the deployment of DG, in conjunction with demand side management (DSM) and storage options in distribution networks, in a "smart-grid" paradigm. Intelligence in these systems is related to the way how these elements exchange information for their operation. This capability is achieved thanks to advances in information and communication technologies (ICT). In several R\&D projects it is studied how DSM and DG can become alternatives to the construction of new transmission lines and contribute to a higher reliability of transmission and distribution networks. Presently, this is also motivated by the fact that the construction of new transmission lines faces often opposition due to environmental, economical and social reasons. However DSM and DG introduce into the power systems new dynamics and behaviours which must be taken into account in the planning and operation of the system. The

This work performed in the frame of the "PREMIO" project funded in part by the French Authority of the Provence Alpes Côte-d'Azur region and driven by the cluster of competences CAPENERGIES. Electricite de France (EDF), the EIFER Institute and MINES ParisTech are partners of this project (http://www.capenergies.fr/index.php?Premio).

978-1-4244-5721-2/10/\$26.00 C2010 IEEE power system must be able to increase its operational flexibility, response and reaction time required by the DSM and DG integration. The change of the paradigm makes active the participation of some actors (Transmission System Operator, Distribution System Operator) and new actors and decision makers are getting involved in the operation and planning of the power system. In this context, it becomes more complex to anticipate the evolution of the power system and to take planning decisions for investments i.e. on the network. Consequently, the extents of integration of DG, the impact of DSM and energy saving programs have to be forecasted at a local or regional scale [2], [3], [4].

For this purpose it is necessary to model the impacts of DSM actions at local scale and assess their effects on the demand profile. The questions arise of how the local effects extrapolate at a larger geographical scale. Are the effects between these two scales cumulative or not? How much do the local specificities influence the assessment of the impacts at a larger scale? Such questions are important for decision makers or distribution system operators in order to define the DSM mechanisms to be applied. To answer such questions, it is important to dispose of the appropriate models to assess the impacts of DSM actions at local and also at lager scale (i. e. supra regional), but also to be able to feed them with the right amount of information to provide coherent results. Models including DG resources, storage operations as well as load management possibilities are needed.

This paper presents shortly the state of the art on the available models for simulating the operation of a power system with DG, storage and DSM actions. Based on the capability to represent the complexity of the system, one model is chosen as basis for our study. The input of the chosen model is representative for this type of analysis. In general information at a macro scale is available whereas existing models follow a bottom-up approach. Increasing the spatial resolution means collecting information at local level, which is a costly process. It is thus important to know which are the input parameters influencing mostly the results and therefore to determine which of them have to be obtained at a better geographical resolution. The paper proposes a methodology to carry out this analysis. It also provides evaluation results based on a real test case - a department area in the south of France (Alpes-Maritimes), where the problems related to the capacity of the network to meet increasing demand are already present. 


\section{GENERAL DESCRIPTION OF THE ENERGY MODEL}

Here the impact from the integration of DG, storage and DSM actions in the planning of distribution networks is of interest. For this purpose it is necessary to model the energy flows in the part of the distribution network of interest. This requires to couple models for the DG production, the storage operation, the renewable production and the load of the power system. The combination of such models composes a general energy model that we call here "Energy Planning Evaluation Model (EPEM)".

To select an EPEM for the purposes of this work, the state of art of existing models has been analyzed. References [6], [7], [8] present classifications of energy models of which results can be used to measure the impacts of DSM actions. For instance, we can cite:

- LEAP which is an energy planning model that covers energy demand, transformation and supply. It uses a simulation approach to represent the current energy situation for a given area and to develop forecasts for the future under some assumptions.

- EFOM which is a detailed technological model for the energy system that follows a general system optimization methodology.

- MAED which is a simulation model for evaluating the energy demand implications (in the medium and long term) of a scenario describing a hypothesized evolution of the economic activities and of the lifestyle of the population.

Most of them are based on an energy model suited to the studied system to assess the demand of a given area, considering a reference situation, and then generating different scenarios. The impact assessment of a specific DSM program can be obtained by comparing the reference scenario (without DSM) with the DSM actions scenario. Traditionally, these models favored a description of the system with a macroscopic view. When applied to the local area, these tools work partly from aggregated or averaged input data (for instance national averaged data apply to a local scale, such as a municipality). Indeed, it is difficult to have a local value for each parameter, thus some approximations have to be done. However, we assume that the lack of precision in the local definition of the territorial specificities (i.e. relative to demography, economical activities, climatology, social aspects, etc) could have significant effects on the DSM impact assessment. Consequently, the aim in this work is to verify if improvement of the resolution at the local scale of the input data used in such tools is a required condition to have appropriate and good quality results.

From the state of the art review, an energy model was selected based on the following criteria: (i) characteristics of modeling, (ii) ability of the model to depict local specificities of a territory (region, municipality,...), (iii) scalability of the model i.e. applicability at different geographical scales, (iv) progressive characteristics adaptable to the study case.
The chosen EPEM model was CharTer which is currently used in energy consulting activities ${ }^{1}$ in France. This model was built to assess the demand in energy and power from national to municipal scale at the level of subtransmission substation. Detailed information on the model is presented in [9] and [10].

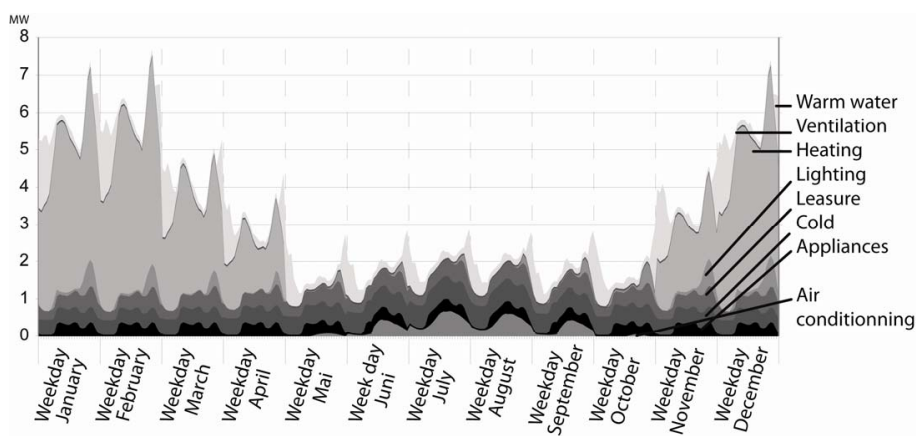

Figure 1 - Ouput type of selected model - A load curve on a given area

The CharTer model calculates the load curve on a given area by cumulating the demand profiles per activity sector of the different usages. The output is illustrated in the Figure 1. The modeling structure is based on a bottom-up approach of the energy system [10].

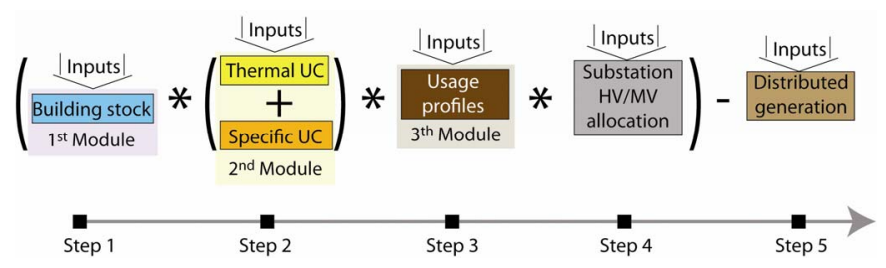

Figure 2 - General structure of the model

The model consists of five main steps shown in Figure 2:

- Step 1: assessment of building stock of residential and tertiary sectors. For a given area, this part assesses the number of residential accommodations in 25 typologies and the surface of tertiary activities by 8 branches. Part of the data used is listed in Table 1.

- Step 2: assessment of the yearly energy consumption for each usage and subsector (residential typology and tertiary branches). Combining the equipment rate, the average power of the equipment, and the use-time of the equipment per usage (Table 1), this part assesses the unitary consumption (UC) in $\mathrm{kWh} / \mathrm{m}^{2}$ for each 13 usage and for each subsector. The annual energy consumption is calculated by multiplying each UC by the previously defined determinant in Step 1.

- Step 3: assessment of the yearly net load curve for a given area. In this step, annual normalized profiles of consumption for each usage and subsector are constructed. They are composed by typical days. Normalization is made upon the total amount of annual energy. The load curve is

\footnotetext{
${ }^{1}$ www.energies-demain.com
} 
calculated by multiplying the annual energy consumption by respective profiles for each usage and their aggregation.

- Step 4: allocation is made of the net load curve of a given area delivered by subtransmission substations, based on the number of residential contracts connected to each substation.

- Step 5: assessment of the gross power passing through the substation, which is obtained by subtracting the distributed production connected to the line to the net load curve.

The model is performed according to the following equations:

$$
\begin{aligned}
& P_{\text {GrossLoadCurve }}(t, y, s)=P_{\text {NetLoadCurve }}(t, y, s)-P_{D G}(t, y, s) \\
& \text { where } y \text { is a given year } \\
& s \text { is the substation } \\
& t \text { is the time unit (hour) } \\
& P \text { is the required load (demand) of a territory (MW) }
\end{aligned}
$$

$P_{\text {NetLoadCurve }}(t, y, s)=\sum_{a=1}^{N_{a}} \beta\left(a_{i}, s\right) \cdot P\left(t, y, a_{i}\right)$

where $a$ is a given geographical unit (e.g. one municipality or one region) $N_{a}$ is the number of unit in the considered area $\beta$ is the share of the power of a given unit by substation

$P(t, y, a)=\sum_{u=1}^{N_{u}} \sum_{s s=1}^{N_{s s}} E_{\text {consumption }}(u, s s, y, a) * \operatorname{Pf}(t, u, s s, y, a)$

where $u$ is one out of the $\mathrm{N}_{\mathrm{u}}$ usages (equal to 13 in our study) considered (heating, air conditioning,...)

ss is one out of the $\mathrm{N}_{\mathrm{ss}}$ sub sectors (equal to 33 in our study) considered

$P f$ is the usage profiles as a function of as a function of usage, subsector, given area and year.

$E_{\text {consumption }}$ is the energy consumed

$\left.E_{\text {consumption }}(u, s s, y, a)=U C(u, s s, y, a)\right) * B S(s s, y, a)$

where $B S$ is the determinant in number of household by residential typology or number of square meter by tertiary branch

$U C$ is the unitary consumption per square meter of a household $\left(\mathrm{kWh} / \mathrm{m}^{2}\right)$

The model delivers results such as the load-curve of the area at the substation level (see Figure 2). From this curve we calculated three synthetic outputs:

1. the total annual energy consumption defined as:

$$
E_{\text {consumption }}(y, a)=\sum_{u=1}^{N_{u}} \sum_{s s=1}^{N_{s s}} E_{\text {consumption }}(u, s s, y, a)
$$

2. the load factors defined as:

$$
\operatorname{LoadFactor}(y, t)=\frac{<P(., y, t)\rangle_{t}}{\operatorname{Max}_{t} P(., y, t)}
$$

3. the ratio between the winter and the summer peaks as:

$$
\text { RatioPeakW } / S=\frac{\underset{t \in \text { Winter }}{\operatorname{Max}} P(., y, t)}{\underset{t \in \text { Summer }}{\text { Max }} P(., y, t)}
$$

The overall model composed by the above equations is statistical, i.e. the description of the system is realized from statistical data sources. The values of the input parameters used

\begin{tabular}{|c|}
\hline Name of parameter $-1^{\text {st }}$ Module \\
\hline Population increase between 2005 and $2030(\%)$ \\
\hline Household increase between 2005 and $2015(\%)$ \\
\hline Averaged size of household in 2015 (number of people per household) \\
\hline Weighting coefficient to extrapolate the data of partial survey \\
\hline Destruction rate of house per year $(\%)$ \\
\hline Electrification of heating usage in new individual principal houses (\%) \\
\hline Electrification of heating usage in new secondary houses $(\%)$ \\
\hline Electrification of heating usage in new collective buildings $(\%)$ \\
\hline $\begin{array}{l}\text { Annual conversion rate from combustible heating systems to electric } \\
\text { heating systems }(\%)\end{array}$ \\
\hline Annual growth rate of tertiary surfaces* $(\%)$ \\
\hline Percentage of individual accommodation in secondary residence $(\%)$ \\
\hline Percentage of installed heating pumps of France in PACA region $(\%)$ \\
\hline Number of installed heating pumps in all France per year \\
\hline $\begin{array}{l}\text { Ratio heating system consumption in individual residence between } \\
\text { combustible and heat pump (\%) }\end{array}$ \\
\hline Name of parameter $-2^{\text {nd }}$ module \\
\hline Annual energy saving of heating in existing houses $(\%)$ \\
\hline Energy saving of heating in new construction (thermal regulation) \\
\hline Annual energy saving of warm water in existing houses $(\%)$ \\
\hline $\begin{array}{l}\text { Ratio energy consumption of warm water between new and old } \\
\text { constructions }(\%)\end{array}$ \\
\hline Energy saving of warm water in new constructions $(\%)$ \\
\hline Equipment rate (nb equipment per unit of building stock) \\
\hline Average power of the equipment \\
\hline Times use of the equipment per year? \\
\hline Energy saving of cooking in existing tertiary surface $(\%)$ \\
\hline Energy saving of cooking in new tertiary surface $(\%)$ \\
\hline Energy saving of warm water in existing tertiary surface (\%) \\
\hline Energy saving of warm water in new tertiary surface $(\%)$ \\
\hline Energy saving of heating in existing tertiary surface (\%) \\
\hline Energy saving of heating in new tertiary surface $(\%)$ \\
\hline Evolution of public lighting consumption (\%) \\
\hline Name of parameter $-3^{\text {rd }}$ module \\
\hline Usage profiles \\
\hline Yield of Heating Pump (Coefficient Of Performance) \\
\hline Climate correcting of air conditioning and heating profile \\
\hline Occupation rate of secondary for leasure \\
\hline
\end{tabular}
by the model come mainly from surveys, measurements and research studies. A first review of these inputs shows that some of them are already locally defined. The Table 1 lists the input parameters by module for which the resolution at the local scale could be a priori improved.

TABLE I. LIST OF THE MAIN INPUT PARAMETERS CONSIDERED IN THE RESOLUTION ENHANCEMENT PROCESS

Ideally, all these parameters should be defined at the local scale. However, we assume that the local definition of each input parameter does not have the same impact on the final result. So first of all, we have to select which are the most relevant parameters to be defined locally. 


\section{METHODOLOGY TO SELECT THE MOST INFLUENTIAL INPUT PARAMETERS FOR STUDY AT LOCAL SCALE.}

Our aim is to identify which are the most relevant parameters of the reference model to define at the local scale. How could this relevance be measured?

Note that the model is improved in the way that some inputs parameters are not locally defined, i.e., these parameters take the same value whatever the territory considered (e.g. the parameter in Table I), the relevance is measured from two indicators:

- the weight of each parameter in the model. Indeed the variation of each input parameter generates more or less variation on output indicators according to its sensitivity.

- $\quad$ the statistical variance of the values by parameter, which means that each parameter admits an interval of value representing its spatial or temporal variability on a given area.

Thus a parameter will be even more relevant when it has an important statistical variability and a significant sensitivity in the model.

As a consequence we identify which input parameters are the most important with respect to the uncertainty in outputs. The sensitivity analysis on the input parameters is the best way to measure the importance of each parameter in the model [13]. There are different ways to carry out a sensitivity analysis [14]. The choice should be determined by several conditions: (i) the finality of the analysis, (ii) the number of the input parameter occurrences, (iii) the relation between the inputs, (iv) the relation between the input and the output parameters.

For our purpose, the model is structured into different modules each processing different input data as described previously in Figure 2. The sensitivity analysis is made partially for the various modules, that is, the sensitivity analysis is performed considering different inputs and outputs data with suitable methods. We consider in this paper the module of building stock and the module of the usage profile.

\section{A. The building stock module analysis}

For this module, we have analyzed the effects of the input parameters for the three outputs (see following $\S$ "Setting the analysis"). The applied methods for this analysis are based on a black box approach. It means that the analysis will be applied without assuming knowledge of the model structure and equation [15]. This choice is justified by the analysis of the relation between the input and output parameters that shows the nonlinearity of their relation. Furthermore, the second and third observed output (respectively the equations 6 and 7) are not continuous. Taking into account the number of input parameter occurrences, a Monte Carlo analysis has been chosen [15]. Consequently, for each input, a min and a max feasible value (interval endpoints) have been defined together with a probabilistic distribution (see Table 3).
The following procedure has been then applied:

Step 1) Definition of the interval endpoint and probabilistic distribution

Step 2) Generation of a sample of values for each parameter using Monte Carlo

Step 3) Propagation of the sample through the module to produce a mapping of the output.

Step 4) Determination of sensitivity of inputs through the correlation analysis between inputs and outputs

Step 5) Determination of significance test through the coefficient of significance

Step 6) Ranking of the inputs with respect of previous calculated values of sensitivity.

\section{$\underline{\text { Settings of input parameters }}$}

As mentioned before, each input parameter has been analyzed on an appropriate interval endpoint and following a suitable probabilistic distribution. When possible, we have assigned realistic values, as we can see in Table III.

TABLE II.

EQUATION OF THE COEFFICIENT USED (CF. [17])

\begin{tabular}{|c|c|c|c|c|c|}
\hline \multirow{3}{*}{\multicolumn{2}{|c|}{$\begin{array}{l}\text { Analyzed input parameter of } \\
\text { building stock module }\end{array}$}} & \multicolumn{4}{|c|}{ Probabilistic distribution tested } \\
\hline & & \multirow[b]{2}{*}{ Type } & \multirow{2}{*}{$\begin{array}{l}\text { Nominal } \\
\text { value }\end{array}$} & \multicolumn{2}{|c|}{$\begin{array}{l}\text { Interval } \\
\text { endpoint }\end{array}$} \\
\hline & & & & $\begin{array}{l}\text { Low } \\
\text { value }\end{array}$ & $\begin{array}{l}\text { High } \\
\text { value }\end{array}$ \\
\hline \multicolumn{2}{|c|}{$\begin{array}{l}\text { Population evolution between } \\
2005 \text { and } 2030(\%)\end{array}$} & Gaussian & 17,1 & 14,1 & 20,1 \\
\hline \multicolumn{2}{|c|}{$\begin{array}{l}\text { Household evolution between } \\
2005 \text { and } 2015(\%)\end{array}$} & Gaussian & 7,04 & 5,88 & 8,2 \\
\hline \multicolumn{2}{|c|}{$\begin{array}{l}\text { Averaged number of people by } \\
\text { household in } 2015\end{array}$} & Gaussian & 2,155 & 2,15 & $2,1-$ \\
\hline \multicolumn{2}{|c|}{$\begin{array}{l}\text { Rate of collective house in } \\
\text { principal residence in } 2005 \text { for } \\
\text { all the communes }(\%)\end{array}$} & Gaussian & 51,24 & 50,71 & 51,76 \\
\hline \multicolumn{2}{|c|}{$\begin{array}{l}\text { Rate of individual house in } \\
\text { secondary residence }(\%)\end{array}$} & Gaussian & 22,73 & 22,13 & 23,32 \\
\hline \multicolumn{2}{|c|}{$\begin{array}{l}\text { Weighting coefficient to } \\
\text { extrapolate the data of partial } \\
\text { survey }\end{array}$} & Gaussian & 1,75 & 1,58 & 1,93 \\
\hline \multicolumn{2}{|c|}{$\begin{array}{l}\text { Destruction rate of houses per } \\
\text { year }(\%)\end{array}$} & Triangular & 0,12 & $\begin{array}{c}\text { No } \\
\text { value }\end{array}$ & 0,5 \\
\hline \multirow{3}{*}{$\begin{array}{l}\text { Electrification } \\
\text { of heating usage } \\
\text { in new } \\
\text { accommodations } \\
(\%)\end{array}$} & $\begin{array}{l}\text { Individual } \\
\text { principal } \\
\text { house }\end{array}$ & Triangular & 79 & 10 & $\begin{array}{l}\text { No } \\
\text { value }\end{array}$ \\
\hline & $\begin{array}{l}\text { Individual } \\
\text { secondary } \\
\text { house }\end{array}$ & Triangular & 79 & 15 & $\begin{array}{l}\text { No } \\
\text { value }\end{array}$ \\
\hline & $\begin{array}{l}\text { Collective } \\
\text { house }\end{array}$ & Triangular & 79 & 15 & $\begin{array}{l}\text { No } \\
\text { value }\end{array}$ \\
\hline \multicolumn{2}{|c|}{$\begin{array}{l}\text { Conversion rate of heating } \\
\text { system from combustible to } \\
\text { electric }(\%)\end{array}$} & Gaussian & 2 & 0 & $\begin{array}{l}\text { No } \\
\text { value }\end{array}$ \\
\hline \multirow{7}{*}{$\begin{array}{l}\text { Annual growth } \\
\text { rate of tertiary } \\
\text { branches }(\%)\end{array}$} & CAHORE & Triangular & 1,5 & 10,11 & $-2,1$ \\
\hline & School & Triangular & 1,40 & 5,53 & 2,05 \\
\hline & Health & Triangular & 0,8 & 2,95 & 1,09 \\
\hline & Office & Triangular & 2,4 & 11,02 & 0,86 \\
\hline & Transpo & Triangular & 2,2 & 4,98 & $-4,58$ \\
\hline & Commerce & Triangular & 0,8 & 10,97 & $-0,02$ \\
\hline & SLC & Triangular & 2 & 11,77 & 0,53 \\
\hline
\end{tabular}




\begin{tabular}{|c|c|c|c|c|c|}
\hline \multirow{2}{*}{\multicolumn{2}{|c|}{$\begin{array}{l}\text { Analyzed input parameter of } \\
\text { building stock module }\end{array}$}} & \multicolumn{4}{|c|}{ Probabilistic distribution tested } \\
\hline & & \multirow{2}{*}{$\begin{array}{c}\text { Type } \\
\text { Triangular }\end{array}$} & \multirow{2}{*}{$\begin{array}{c}\begin{array}{c}\text { Nominal } \\
\text { value }\end{array} \\
0,8\end{array}$} & \multicolumn{2}{|c|}{$\begin{array}{l}\text { Interval } \\
\text { endpoint }\end{array}$} \\
\hline & $\begin{array}{l}\text { Community } \\
\text { house }\end{array}$ & & & 10,54 & 3,79 \\
\hline \multirow[b]{2}{*}{ Heating pump } & $\begin{array}{l}\text { Number of } \\
\text { installed in } \\
\text { France }\end{array}$ & Triangular & 66.060 & $\begin{array}{c}\text { No } \\
\text { value }\end{array}$ & 72.500 \\
\hline & $\begin{array}{ll}\text { Ratio } & \text { of } \\
\text { installed } & \text { in } \\
\text { PACA } & \\
\text { region } & \end{array}$ & Triangular & 0,09 & 0,08 & $\begin{array}{c}\text { No } \\
\text { value }\end{array}$ \\
\hline
\end{tabular}

The determination of this setting was done from statistical analysis on different data sources. The method used is related to the statistical uncertainty or the statistical variation inside the case study.

\section{The correlation coefficient}

Several studies have already dealt with the correlation coefficients for the determination of the sensitivity of input parameters in the frame of a black box approach [12], [14], [15] and [16]. As we can notice from these works, each of them are fitted to a specific relation (linearlnonlinear, monotonicity \non-monotonicity) between input and output variables. For our analysis we have selected three regressioncorrelation measures:

- The Pearson correlation coefficient is based on the direct linear correlation between the sampled value of the input and output.

- The Spearman Rank-Order Correlation Coefficient is based on the linear correlation between the rank orders of the input and the output (cf. [18])

- The Kendall's Tau analysis is based on the relative ordering of ranks between the two variables (cf.[18])

In the follow, these three calculations will be designated as correlation coefficients. For more information about these three coefficients, we refer to many books on statistics e.g. [18] and practical implementation given in [17].

All these methods are suitable to measure the correlation of specific relations between two variables. We assume that the joint assessment of three correlation coefficients for each relation input/output enables to have a good appreciation of the relation between inputs and outputs. But each value should be weighted by a significance coefficient able to determine if the sampled values are fortuitous or not.

\section{The coefficient of significance}

In order to validate the results of the previous correlation coefficients, coefficients of significance were calculated for which the distribution value in uncorrelated data case is known. The following table indicates for each one, the equation of significance coefficient and its reference distribution as well.
TABLE III. EQUATION OF THE COEFFICIENT USED (CF. [17])

\begin{tabular}{|l|c|c|}
\hline \multicolumn{1}{|c|}{$\begin{array}{c}\text { Correlation } \\
\text { Coefficient }\end{array}$} & $\begin{array}{c}\text { Equation of coefficient of } \\
\text { significance }\end{array}$ & $\begin{array}{c}\text { Reference } \\
\text { distribution }\end{array}$ \\
\hline $\begin{array}{l}\text { Pearson } \mathrm{R}_{\mathrm{p}} \\
\text { (on variable } \\
\text { values) }\end{array}$ & $t=r_{p} \sqrt{\frac{N-2}{1-r_{s}^{2}}}$ & $\begin{array}{c}\text { Student's } \\
\text { distribution (with N- } \\
2 \text { degrees of } \\
\text { freedom) }\end{array}$ \\
\hline $\begin{array}{l}\text { Spearman } \mathrm{r}_{\mathrm{s}} \\
\text { (on rank of } \\
\text { variable values) }\end{array}$ & $t=r_{s} \sqrt{\frac{N-2}{1-r_{s}^{2}}}$ & $\begin{array}{c}\text { Student's } \\
\text { distribution (with N- } \\
2 \text { degrees of } \\
\text { freedom) }\end{array}$ \\
\hline $\begin{array}{l}\text { Kendall } \tau \text { of order of the } \\
\text { (on ord } \\
\text { rank of the } \\
\text { variable values ) }\end{array}$ & $t=\sqrt{\frac{4 N+10}{9 N(N-1)}}$ & Normal distribution \\
\hline
\end{tabular}

Taking into account the reference distribution, we have calculated for each coefficient of significance the probability that the correlation coefficient is fortuitous i.e. the probability that the coefficient of significance achieve the value with statistical uncorrelated data.

$\underline{\text { Settings of the analysis }}$

Based on the reproducibility analysis carried out in [16], a threshold of 500 runs seems to be the acceptable minimum to prevent having to many variances of the results between the different simulations. Considering [18], this threshold has to be exceeded to have a sampled value close to the reference distribution. As a consequence, we have decided to double the number of required runs, which is a compromise between the minimum requirement and the calculation time. Taking into account the possible interdependency of the input parameters and the nonlinearity of the relation between the inputs and the outputs, all the parameter readings were taken at the same time.

\section{B. Results}

The results coming from the module of determinant can be presented in two steps.

- First, the sampled analysis and their output variation effects measured from correlation and significance test.

- Secondly, the ranking of the parameter based on correlation and significance coefficient values, as depicted in Figure 3.

Table IV shows some correlation coefficient by couple inputloutput. The second column is the probability that the sampled distribution peculiar to each input is not fortuitous. Notice that these calculations have been done for each analysis - Pearson, Spearman and Kendall.

TABLE IV.

SPEARMAN ANALYSIS RESULTS

\begin{tabular}{l|c|c|c|c|c|c|}
\hline \multicolumn{2}{|c|}{} & \multicolumn{2}{|c|}{ Total energy } & \multicolumn{2}{c|}{ Load factor } & \multicolumn{2}{c|}{ Rapport peak W/S } \\
\cline { 2 - 7 } & $\begin{array}{l}\text { Correl. } \\
\text { coef. }\end{array}$ & $\begin{array}{c}\text { Signific. } \\
\text { test }\end{array}$ & $\begin{array}{c}\text { Correl. } \\
\text { coef }\end{array}$ & $\begin{array}{c}\text { Signific. } \\
\text { test }\end{array}$ & $\begin{array}{c}\text { Correl. } \\
\text { coef }\end{array}$ & $\begin{array}{c}\text { Signific. } \\
\text { test }\end{array}$ \\
\cline { 2 - 7 } P1 & 0,02 & 0,49 & 0,06 & 0,92 & 0,04 & 0,77 \\
\hline P2 & 0,02 & 0,49 & 0,05 & 0,74 & 0,04 & 0,77 \\
\hline P3 & $-0,01$ & 0,26 & 0,03 & 0,61 & $-0,03$ & 0,62 \\
\cline { 2 - 7 } P4 & 0,04 & 0,78 & 0,05 & 0,72 & 0,01 & 0,32 \\
\hline
\end{tabular}




\begin{tabular}{r|c|c|c|c|c|c|}
\cline { 2 - 6 } P5 & 0,28 & 1,00 & 0,16 & 1,00 & 0,40 & 1,00 \\
\cline { 2 - 7 } P6 & $-0,33$ & 1,00 & $-0,35$ & 1,00 & $-0,23$ & 1,00 \\
\cline { 2 - 7 } P7 & 0,01 & 0,13 & 0,02 & 0,41 & $-0,01$ & 0,14 \\
\cline { 2 - 7 } P8 & 0,07 & 0,96 & 0,04 & 0,67 & 0,04 & 0,80 \\
\cline { 2 - 7 } P9 & 0,26 & 1,00 & $-0,05$ & 0,74 & $-0,12$ & 1,00 \\
\cline { 2 - 7 } P10 & 0,05 & 0,91 & $-0,03$ & 0,62 & $-0,01$ & 0,36 \\
\cline { 2 - 7 } P11 & $-0,02$ & 0,55 & 0,01 & 0,25 & 0,02 & 0,45 \\
\cline { 2 - 7 } P12 & $-0,03$ & 0,63 & 0,06 & 0,75 & $-0,02$ & 0,39 \\
\cline { 2 - 7 } P13 & $-0,02$ & 0,55 & 0,02 & 0,45 & $-0,02$ & 0,38 \\
\cline { 2 - 7 } P14 & 0,65 & 1,00 & $-0,31$ & 0,86 & $-0,17$ & 1,00 \\
\cline { 2 - 7 } P15 & 0,07 & 0,97 & $-0,01$ & 0,21 & 0,00 & 0,09 \\
\cline { 2 - 7 } P16 & 0,02 & 0,49 & 0,06 & 0,92 & 0,04 & 0,77 \\
\cline { 2 - 6 } P17 & 0,02 & 0,49 & 0,05 & 0,74 & 0,04 & 0,77 \\
\hline
\end{tabular}

To select the most sensitive parameters, we have done a ranking of the parameters, from a weighted sum of the different correlation coefficients. The procedure adopted for the ranking of the parameter is:

Step 1) Convert absolute correlation coefficient value into rank for each input parameter. So each input has a maximum of three rank values.

Step 2) Calculate for each input a score as

Score $(n)=\sum_{k=1}^{L} P_{c c}(n, k) * \operatorname{Rank}(n, k)$

where $C C$ means Correlation Coefficient, $P_{c c}$ is the coefficient of probability defined in $\S$ "The coefficient of significance" $\operatorname{Rank}(n, k)$ is the ranking of CC $(\mathrm{n}, \mathrm{k})$ in $[\mathrm{CC}(., \mathrm{k})]$ $N$ is the number of input parameter and $\mathrm{n} \in[1, \mathrm{~N}]$ $L$ is the number of output parameter and $\mathrm{k} \in[1, \mathrm{~L}]$

This procedure gives the following sensitivity rankings of input depicted in abscissa of Figure 3. This one was done from the score values. On this graph, we have also depicted the variation rate of score value between the parameters. We observe some grouping of parameters with close sensitivity (when the variation rate is relatively close to 0 ).

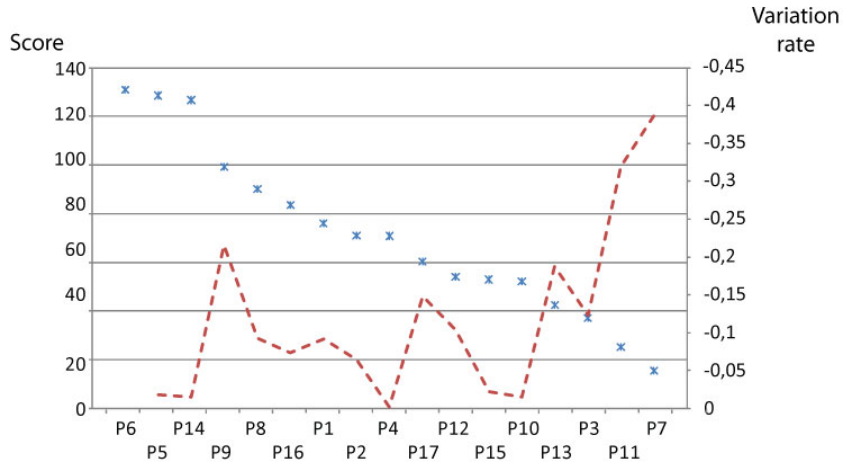

Figure 3 - Ranking results of inputs from 1st module

\section{The profiles module}

Inputs of this module are 20 normalized consumption profiles, by usage and sector. Each one takes into account 12 months per year, and three typical 24-hour days per month, which gives exactly 864 values per profile. Each profile is annually normalized.

To select the most sensitive profiles, another sensitivity analysis approach is adopted: a percentage of variation from base value. So, each profile has been modified through a variation of $\pm 10 \%$ from base value. The variation effects have been measured only on outputs 2 and 3 . In fact, the normalized profiles have the same effect on output 1, being the total annual energy. To measure the sensitivity we have proceeded then, according to following ranking procedure:

Step 1) Calculate for each value of both outputs the percentage of variation from the base value.

Step 2) Average the variation by usage and output

Step 3) Calculate for each output the proportion of variation

Step 4) Convert variation values to rank by output

Step 5) Calculate for each input a ranking score

$$
\begin{aligned}
& \text { Score }(n)=\sum_{k=1}^{L} \operatorname{Rank}(n, k) \cdot \frac{1}{L} \\
& \text { where } L \text { is the total number of profiles }
\end{aligned}
$$

From this procedure, the following sensitivity ranking of inputs is calculated, which shows that the most sensitive profiles are in order: heating in residential sector, lighting in tertiary sectors, then air conditioning and lighting in residential sector.

TABLE V. RANKING RESULTS OF SOME INPUTS FROM $2^{\text {ND }}$ MODULE

\begin{tabular}{|l|c|c|c|}
\hline Usages & Sector & Ranking score & Ranking \\
\hline Heating & $\mathrm{R}$ & 1 & 1 \\
\hline Lighting & $\mathrm{T}$ & 1,5 & 2 \\
\hline Air conditionning & $\mathrm{R}$ & 3 & 3 \\
\hline Lighting & $\mathrm{R}$ & 3 & 4 \\
\hline Ventilation & $\mathrm{T}$ & 3 & 5 \\
\hline Heating & $\mathrm{T}$ & 3,5 & 6 \\
\hline Cold & $\mathrm{R}$ & 4 & 7 \\
\hline Leasure & $\mathrm{R}$ & 5 & 8 \\
\hline Air conditionning & $\mathrm{T}$ & 5 & 9 \\
\hline Cooking & $\mathrm{T}$ & 5 & 10 \\
\hline
\end{tabular}

\section{CONCLUSIONS AND PERSPECTIVES}

The analysis presented here has been carried out on a set of input parameters of a complex model with a large amount of inputs. The diversity of the input parameter types made it necessary to structure the analysis into two different parts, and to therefore provide two sensitivity analysis methods, a Monte Carlo analysis and a percentage variation of the base value.

The Monte Carlo analysis method used provides relevant assessment of sensitivity of inputs on the output, especially in non-linear relation cases, for which it is usually more difficult to establish the relation. It is necessary to note that these results are specific to the case study analyzed. Consequently, it would be interesting to evaluate the proposed methodology in other case studies. 
Based on the ranking results of the parameters, the most relevant have been selected in order to be defined locally and integrated into a model to simulate the local energy effects of setting up a Demand Side Management action.

Furthermore, this research work will contribute to study the impact of a spreading out of smart grid system architectures (such as PREMIO architecture) in a large scale.

\section{ACKNOWLEDGMENTS}

The "Energies Demain" company is acknowledged for having supplied data and support to perform this work.

All the members and contributors of PREMIO project are acknowledged for their helpful collaboration.

\section{REFERENCES}

[1] S. Kärkkäinen et al. "Integration of Demand-Side management, Distributed Generation, Renewable Energy Sources and Energy Storages", Report Task XVII Integration of Demand-Side management, Distributed Generation, Renewable Energy Sources and Energy Storages, Vol. 1, International Energy Agency Demand-Side Management Programme, p. 77, 2009.

[2] R. Janked et al. "Advanced Local Energy Planning", International Energy Agency, Report, Annex 33, Energy Conservation in Building and Community Systems, p. 206, 2000.

[3] G. Bouvier, "Local authorities and electricity - territorie, stakeholders and issues around local utilities in France",Ph.D thesis on Geography (option geopolitics), in french, Institut Français de Géopolitique Université Paris 8, p. 538, 2005.

[4] F.M. Poupeau "Which place for the local authorities in French electrical sector", Journal paper "Gérer et Comprendre", CNRS (LATTS), Annales des Mines, Gérer \& Comprendre, pp. 46 - 502004

[5] N. Van beeck "Classification of energy models", Report, Tilburg university \& Eindhoven University of Technology, p. 25, 1999

[6] L. Solsbery \& J.M Bourdaire et al. "Mapping the energy future", Report Policy analysis series, International Energy Agency, p. 88, 1998

[7] T. Lefevre, "Classification of model for energy and environmental policy analysis", Presentation, Centre for Energy Environment resources Development, Internationl Seminar Sustainable Energy Dévelopment in Thailand : Options and Tools, Bangkok, Thailand, p. 17 2005

[8] N.Pigenet, «Monitoring and electrical demand prediction tools in scale of area, application on Lot department, Phd thesis on electricity, University of Toulouse, p. 227, 2009

[9] L. Cauret, "Dynamics of Demand Side Management : stakeholders and tools in French metropole and overseas department", Phd thesis de l'Ecole des Hautes Etudes en Sciences Sociales, p. 235, 1997

[10] J.N. Swisher, G.d.M Jannuzzi, \& R.Y. Redlinger, "Integrated Ressource Planning - Tools and methods", Report, United Nations Environment Programme, Collaborating Centre on Energy and Environment, Riso National Laboratory, p. 270, 1997

[11] Reseau de Transport Electrique, "Prospective statement of the electrical balance Supply-demand in France", Report, Ed.2009, p. 172, 2009

[12] J.C. Helton, J.D. Johnson, C.J.Sallaberry \& C.B. Storlie,"Survey of sampling-based mathods for uncertainty and sensitivity analysis", Journal paper Reliability Engineering and System Safety 91, Department of Mathematics and Statistics, Arizona State University, pp. 1175-1209, 2006

[13] H. Christopher Frey \& Sumeet R. Patil, "Indentification and review of sensitivity analysis methods", Report, North Carolina State University, Raleigh, p. 75,

[14] A. Saltelli \& T. Homma, "Sensitivity analysis for model output Performance of black box techniques on three international benchmark exercices“, Journal paper Computational Statistics \& Data Analysis 13,
Commission of the European Communities, Joint research Centre, Ispra, Italy, pp. 73-94, 1992

[15] A. Saltelli T.H. Andres \& T. Homma, "Sensitivity analysis of model output - An investigation of new techniques", Journal paper Computational Statistics \& Data Analysis 15,Commission of the European Communities, Joint research Centre, Ispra, Italy, pp. 211-238, 1993

[16] J.C. Helton, F.J. Davis,"Latin hypercube sampling and the propagation of uncertainty in analyses of complex systems", Journal paper Reliability Engineering and System Safety 81, Department of Mathematics and Statistics, Arizona State University, pp. 23-69, 2003

[17] W.H Press, S.A. Teukolsky, W.T. Vetterling \& B. P. Flannery,"Numerical Recipies in C - The Art of Scientific Computing", Book, ISBN 0-521-43108-5, $2^{\text {nd }}$ Ed.Cambridge University Press, 1992

[18] J.P. Lecoutre "Statistic and Probability", Book, ISBN 978-2-10-0533039, $4^{\text {th }}$ Ed., p. 303, 2009 